journal can maintain its present standard of original material, which compares well with at least two of last year's newcomers, and continues to present a broader view of human genetics than some of its competitors, it should do well.

Clinical Dysmorphology differs from most of the other journals that cover human genetics. Although some accept a few papers on developmental abnormalities, this new journal aims to devote itself entirely to publishing reports of multiple congenital anomaly syndromes, together with review articles on the aetiology, clinical definition, genetic mapping and molecular embryology of birth defects.

Until recently, clinical dysmorphology was the Cinderella of clinical medicine and human genetics, and even regarded by some as a rather exotic form of stamp collecting. But not any more. The accurate classification of syndromes in dysmorphology is now an absolutely vital prerequisite to studying the molecular basis of defective fetal development. Many of these conditions, rare though they are, have a clear-cut genetic component. The identification of the gene(s) involved, backed up by studies of the genetic and molecular basis of the many mouse models of the dysmorphology syndromes, is a growing and exciting field.

The early numbers of Clinical Dysmorphology contain a wide variety of well illustrated papers, most of which, inevitably at this early stage, are largely descriptive and comparative. Hence the stated aims of the journal have been met, but only in part. It may be a while before it starts to turn molecular like its fellow journals in human genetics. But this extremely important field has great potential for human developmental biology; it looks as though this journal may have been born at just the right time.

So journal publishing in human genetics appears to be in fine fettle. There is only one cloud on the horizon. As is clear from the lists of editorial and advisory boards of these journals, the same names crop up again and again. It will become increasingly difficult for new journals in this field to obtain invigorating editorial help. But if they are to remain exciting and vital, as well as evolve a style that distinguishes them from the rest of the pack, some of them will have to start to look for younger and less worn names on their covers.

In case any geneticists take this personally, let me hasten to add that these fears were engendered mainly by my discovery that unbeknown to (or, more hopefully, forgotten by) me, I am a member of the editorial boards of several journals of this genre.

David Weatherall is in the Institute of Molecular Medicine, University of Oxford, John Radcliffe Hospital, Headington, Oxford OX3 9DU, UK.

\section{Different strands}

\author{
Joy Delhanty
}

Chromosome Research: An International Journal on the Molecular, Supramolecular and Evolutionary Aspects of Chromosome Biology. Editor-in-chief Herbert Macgregor. Rapid Communications of Oxford. 6/yr. £182, $\$ 310$ (institutional); £90, \$152 (personal).

IN a leading article in its inaugural issue (May 1993), Herbert Macgregor justified the need for this new journal by mentioning that in the previous year there were

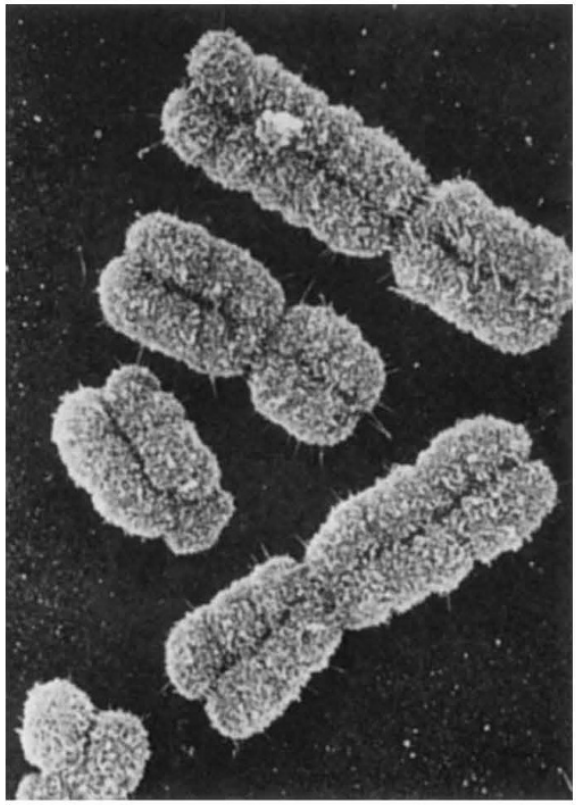

Human chromosomes (SEM).

nearly 7,000 articles on some aspect of chromosome biology scattered among 627 different journals, with room for less than 10 per cent of them in journals welcoming papers on chromosomes or cytogenetics. It is true that chromosome research is in an expansive phase because of the technological revolution of the past decade that has seen the development of confocal microscopy, fluorescence in situ hybridization (FISH) and associated image capture-and-analysis systems. These developments alone justify a new specialist publication.

The journal intends to cover a wide field of investigation into the evolutionary, supramolecular and molecular aspects of chromosome biology and its scope most closely matches that of Chromosoma among existing journals (Cytogenetics and Cell Genetics devotes the lion's share of its space to human gene mapping).

The initial aim of the editors of Chromosome Research was publication within 3 months of receipt, not counting revision time; in the current volume it is working out as 3 to 6 months after revision, but the referees seem to be fairly speedy. The journal publishes mostly medium length papers (10 - 15 printed pages), with occasional short communications and technical reports and the odd book review.

Both the academic and technical quality of the papers are generally high, with a recent issue covering topics as divergent as "Chromosome variation in NW American newts", "Conservation and evolution of centromeric satellite DNA in deer" and "The physical map of a $2 \mathrm{Mb}$ chromosome of the intestinal protozoan parasite Giardia duodenalis", said to be the most primitive eukaryote. For subject matter of this nature the production quality is appropriately excellent, including the colour reproduction. The personal subscription rates give reasonable value for money; there are no free reprints (unlike Chromoso$m a$ ), although authors receive a complimentary copy of the issue in which their contribution appears.

Joy Delhanty is in the Department of Genetics and Biometry, University College London, 4 Stephenson Way, London NW1 2HE, UK.

\section{Start at the beginning}

\section{Jonathan Bard}

Zygote: The Biology of Gametes and Early Embryos. Editor-in-chief Brain Dale. Cambridge University Press. 4/yr. USA, Canada and Mexico \$148, UK £86.

GONE are the days when developmental biology was a small field whose practitioners all knew one another and whose publication needs were met by a few journals. The current flood of papers in the area has led to developmental work being published throughout the biological literature, with new journals being set up to absorb the torrents. Some accept any developmental work that has a strong molecular component, but the latest, Zygote, focuses on the beginnings of embryogenesis across the phyla (in contrast to Molecular Reproduction and Development, which concentrates on early mammalian development). This specialization by topic rather than technique is sensible as molecular approaches in this field are now taken for granted.

One test for deciding whether a relatively narrow area needs an additional journal is to ask if the new publication attracts substantial papers. But because good manuscripts can always find a home, there is a second question that should be asked. Do the workers in the field want to communicate with their peers as well as improve their curricula vitae? The criterion here is whether the editor wishes to include, and can attract, more than just research papers. 